perifèria

Número 20 (2), diciembre 2015

revistes.uab.cat/periferia

\title{
Articulaciones entre memoria, identidad y prácticas musicales: la escucha-apreciación como categoría de alteridad entre el ayer $y$ el hoy
}

\author{
Daniel Ribeiro Medeiros- Universidad Federal de Pelotas (UFPel) ${ }^{1}$
}

Isabel Porto Nogueira-Universidad Federal de Pelotas (UFPel) yUniversidad

Federal del Rio Grande do Sul

DOI: $\underline{\text { http://dx.doi.org/10.5565/rev/periferia.481 }}$

\section{Resumen}

Este artículo tiene como objetivo reflexionar acerca de parte de las evaluaciones/comparaciones que los entrevistados ${ }^{2}$ hacen acerca del pasadoy el presente. A lo largo de la investigación ${ }^{3}$, las hemos comprendido como procesos que establecen una alteridad temporal ${ }^{4}$ basada en una relación entre el ayer (en aquellos días) y el hoy (hoy en día):un eje quelos entrevistados narran y se representan a sí mismos en el hoy a partir de sus experiencias-trayectorias musicales. Además de nuestros principales marcos teóricos, presentaremos la estructura memorial de sentidobasada en dicha alteridadquecontribuye a la construcción de la memoria social de aquellos que participaron de la escena rockunderground pelotense de los 90. Por último, se evidencia la nostalgiacomomarco de pensamiento-interpretaciónque ayuda a entrelazar memoriaeidentidad.

\footnotetext{
1 Enviar correspondencia a: Daniel Ribeiro Medeiros () e Isabel Porto Nogueira (isabel.isabelnogueira@gmail.com).

${ }^{2}$ Nosgustaría agradecer enormemente a los colaboradores que han contribuido con fotos, materiales, testimonios, narrativas y memorias, sin los cuales este trabajo de investigación no sería posible.

${ }^{3}$ Dichas comparaciones-evaluaciones fueron cogidas a través de entrevistas individuales realizadas con sujetos que participaron de la escena rock underground de la ciudad de Pelotas en los noventa.. El proyecto de tesis Rock underground pelotense en los 90: Memoria de una escena subterránea en el extremo Sur de Brasil se realiza dentro del Programa de Postgrado en Memoria Social y Patrimonio Cultural (PPGMP) de la Universidad Federal de Pelotas (UFPel

${ }^{4}$ Con base en el paso del tiempo desde el pasado hasta el presente.
} 


\title{
revista de recerca i formació en antropologia
}

\section{perifèria}

Número 20 (2), diciembre 2015

revistes.uab.cat/periferia

Palabras clave: memoria social, identidad, alteridad, música popular, rock, prácticas musicales, hábitos de escucha.

\begin{abstract}
This paper aims to reflects on part of the evaluations-comparisons collaboratorsinterviewees make about past and present. In the course of our investigation, we have understand it how a process that establishes a kind of temporal alterity based on the relationship between the yesterday (in those days) and the today (nowadays): a kind of pivot through which the interviewees narrate and represent themselves in the today from their musical-life experiences-trajectories.Besides our theoric referentials, we will show the memorial meaning structurethat is contributing to the construction of the social memory of those who participated in the pelotense's rock underground scene in the 90s. At last, is evidenced that the nostalgia participates like a thought framework that helps to interweave memory and identity.
\end{abstract}

Keywords: social memory, identity, alterity, popular music, rock, musical practices, habitus of listening.

\section{Introducción}

Aunque el proyecto de tesis doctoral Rock underground pelotense en los 90: Memoria de una escena subterránea en el extremo Sur de Brasil ${ }^{5}$ esté relacionado con las historias de vida musicales individuales de nuestros colaboradores hacia la conformación de la escena rock underground de la ciudad de Pelotas (Brasil) en los noventa, hemos percibidoque en algunos puntos temáticos de sus narrativas surgeninterpretaciones y representaciones ${ }^{6}$ (compartidas) que son construidas a través de comparaciones entre el ayer y el hoy.A través de dicho dialogoarticulación temporal (ayer-hoy)entrelazan el trabajo de la memoria a la construcción de una identidad cultural y colectivadel nosotros-ayer ${ }^{7}$ en el presente.

\footnotetext{
${ }^{5}$ Este trabajo de investigación tiene la financiación de la CAPES (Coordinación de Perfeccionamiento de Personal de nivel Superior)/Brasil.

${ }^{6}$ Son las "teorías de la gente, del sentido común y del conocimiento del cada día". Es lo que "llamamos representaciones sociales" (Wagner 1995 apud Wagner 1995: 1).

7 Es decir: un nosotros que, aunque viven el presente, han participado de un pasado por lo cual los otros-hoy no han pasado.
} 


\section{perifèria}

Número 20 (2), diciembre 2015

revistes.uab.cat/periferia

Nuestra investigación se apoya en la perspectiva de la antropología de la memoria (Candau 2005; 2011), la que, ubicada "en el punto de paso entre el sujeto y el grupo", busca "comprender [...] cómo los sujetos" comparten "prácticas, representaciones, creencias, recuerdos, produciendo [...] lo que llamamos cultura" (Candau 2011:11).

La articulación temporal vista arriba se caracteriza como una especie dealteridad temporal: una diferenciación (reconocimiento o reivindicación) entre nosotros-ayer respecto a los otros-hoy. La construcción de dicha alteridadocurre a lo largo de variadas comparaciones entre marcos socio-musicales ${ }^{8}$ pasados y presentes, manifestando, por lo tanto, la premisa del diálogo que ocurre en el trabajo de la memoria(Halbwachs 2004 [1925]; 1990; Candau 2011): lamemoria se conforma a través de la "reconstrucción de los recuerdos desde el presente", en un intercambio entre los esbozos de los recuerdos-imágenes ${ }^{9}$ acerca del pasado y el conjunto de "nociones y percepciones" que llenan la consciencia actual de los sujetos (Halbwachs 2004 [1925]: 133).

En dicho diálogo, lanostalgia ${ }^{10}$ emerge entrelazando sujetos, sociedades y contextos en tiempos distintos, ayudando en la inseparabilidad entre memoriaeidentidad (Candau 2011; Pollak 1992):

Los fallos de memoria, los olvidos y los recuerdos cargados de emoción estánsiempre vinculados a una consciencia que obra en el presente. Porque la memoria organiza "los trazos del pasado en función de los compromisos del

\footnotetext{
${ }^{8}$ Relaciones entre sociedad y aspectos económicos, culturales, materiales, aprendizajes, etc.

9Los recuerdos-imágenes no son imágenes "fotográficas" de los sucesos pasados. Al contrario, se conforman a través delentrelazamientode imágenes ("los continentes", en el sentido metafóricogeográfico) e ideas ("los contenidos"): las imágenes están contenidas en las ideas así como las ideas están contenidas en las imágenes (Halbwachs 2004 [1925]: 326). O sea, las ideas (que emergen de la acción de idear, en el momento presente del recuerdo) ayudan en la (re)construcción de las imágenes acerca del pasado así como las imágenes (re)construidas anteriormente ayudan a manejar ideas en nuevos actos de rememoración.

${ }^{10}$ La nostalgia será planteada en un apartado más abajo.
} 


\section{revista de recerca i formació en antropologia}

\section{perifèria}

Número 20 (2), diciembre 2015

\section{revistes.uab.cat/periferia}

presente y luego por demandas del futuro", debemos ver en ella menos "una función de conservación automática invertida por una consciencia sobrepuesta" que un modo esencial de la consciencia misma, lo que caracteriza la interioridad de las conductas. El recuerdo no "contiene" la consciencia, pero la evidencia y la manifiesta, es "la consciencia misma que experimenta en el presente la dimensión de su pasado" (Candau 2011:63).

Es desde ahí que emerge la antedicha alteridad temporal.

Por lo tanto, desde el punto de vista de la antropología de la memoriaes significativa la función de las enunciaciones nostálgicas, pues ayudan a establecer un diálogo entre pasado-presente y el enlace entre memoriaeidentidad.

\section{Planteamiento teórico-metodológico}

Además de los presupuestos generales de la historia de vida (Ferreira; Amado 1998; Jovchelovitch; Bauer 2002; Alberti 2000; Bolívar; Lindon 1999; Domingo; Fernández 2001), nuestra investigación está basada en el juego existente entre las representaciones factuales y semánticas en la construcción de la memoria social:las primeras son "representaciones relativas a la existencia de ciertos hechos", mientrasque las últimas son "representaciones relativas a los sentidos atribuidos a estos mismos hechos" (Candau 2011:39). De ese modo, nuestro enfoque se basa en el sentido etnográficoplanteado por Geertz (2008): el "esfuerzo intelectual" que lleva a la descripción densa. O sea, el movimiento que parte desde las descripciones factualeshacia los sentidos socioculturales (Geertz 2008:4).Por lo tanto, es un proceso de profundización de los aspectos descriptivo-factuales los cuales permiten acceder a los niveles semánticos y simbólicos de lacultura.

Además de ello, nuestro esfuerzo también se basa en la perspectiva según la cual"solamente un 'nativo' hace la interpretación de primera mano", mientras que las interpretaciones de los investigadores son hechas de segunda, tercera, etc, 


\section{perifèria}

Número 20 (2), diciembre 2015

revistes.uab.cat/periferia

mano.El conocimiento, entonces, se construye bajo la superposición de capas de interpretaciones (Geertz 2008:11) ${ }^{11}$.

Lo que se pretende con el planteamientode este artículo es, a través de aquellas personas cuyas trayectorias musicales estaban mezcladas a sus participaciones en la escena rock underground pelotense de los 90, comprender la estructura de sentidoque sostiene parte del tejido memorial colectivo dentro de la inseparabilidad entre memoriaeidentidad. Aunque dichas estructuras sean comúnmente complejas, sobreponiéndose, atándose entre sí, mostrándose "extrañas, irregulares y oscuras", presentándose como manuscritos llenos de "elipsis" e "incoherencias" (Geertz 2008:7), hemos percibido que cada narrativa individual se entrelaza a las narrativas de los otros colaboradores a través de la nostalgia.

\section{La nostalgia}

La nostalgia es un proceso activo en la significación del pasado. En un contexto de "pérdida endémica en la modernidad y modernidad tardía" (Pickering; Kinghtley 2006:919), se caracteriza como una "alternativa viable a la aceleración del tiempo histórico", posibilitando el "diálogo con el pasado" y la búsqueda-reconocimiento del "valor de las continuidades en contrapunto a lo que es efímero, transitorio e incierto"12. Además de ser un instrumento de reordenación-reflexión de sí, de la trayectoria de vida (Pickering; Kinghtley 2006:922), es una "experiencia universal" que se mantiene a lo largo de la vida(sea individual o colectiva)(Sedikides et al. 2004:202). Tiene una "estructura afectiva", funciones existenciales y se constituyecomo un ejercicio de "búsqueda por identidad y significado" (Sedikides et al. 2004:202-203). Y, aunque la nostalgia personal ${ }^{13 "}$ envuelva directamente el self", posee la perspectiva de lo social: una de sus funciones existenciales está en

\footnotetext{
${ }^{11}$ La misma perspectiva de la autoridad compartida de Portelli (2010).

12 O sea, en la medida en que las experiencias del tiempo-espacio son cada vez más percibidas como dimensiones reducidas-comprimidas (Hall 2011: 67-68).

${ }^{13}$ Los autores también presentan la categoría "nostalgia grupal".
} 


\section{perifèria}

Número 20 (2), diciembre 2015

revistes.uab.cat/periferia

la"conectividad" del sujeto con la dimensión delo social ${ }^{14}$, de donde emerge el significado (Sedikides et al 2004:204).

Su principal rasgo es el diálogo entre presente y pasado (Pickering; Kinghtley 2006; Sedikides et al 2004) ${ }^{15}$, donde las comparaciones-evaluaciones acerca de las "experiencias pasadas y corrientes" pueden ser directas-explícitas o indirectasimplícitas (Davis apud Sedikides et al 2004:205). Dichos diálogos presentan tipos básicos de manifestación:(1) un presente negativo versus un pasado positivo o (2) la ambigüedad (Pickering; Kinghtley 2006:925); la (3) redención ("la historia avanza de una escena de vida mala o difícil hacia una de buena y triunfante [...]") 0 (4) la contaminación, (donde el pasado es "deteriorado, arruinado, contaminado" por el presente) (Sedikides et al. 2004:205).

En la medida en que implica un juego en que el afecto se relaciona con las funciones existenciales vitales ${ }^{16}$ (Sedikides et al. 2004:205), la nostalgiatiene que ver con la construcción de la identidad. De este modo, puede ayudar en el proceso de totalización existencial, que es:"un acto de memoriaque invierte de sentido [...] los trazos mnésicos dejados por el pasado" en la construcción de "una imagen satisfactoria de uno mismo". Dicha totalización no es totalmenteindividual: "La forma de la narrativa, que especifica el acto de rememoración, 'ajusta inmediatamente uno mismo a las condiciones colectivas de su expresión'" (Candau 2011:77).A través de las "estrategias distales ${ }^{17 ",}$ la nostalgia, por lo tanto, ayuda tanto a la comprensión del selfpor uno mismo, como acerca el mismo sujeto a las visiones de mundo colectivas, reforzando sus vínculos relacionales con lo social (por ejemplo, a los grupos en los cuales el sujeto ha participado) (Sedikides et al. 2004: 206).

\footnotetext{
${ }^{14}$ Ya sea en el presente o en el pasado.

${ }^{15}$ Así como las premisas de la reconstrucción de la memoria que hemos visto más arriba.

${ }^{16}$ Para más detalles, ver Sedikides et al. (2004: 206-207).

${ }^{17}$ En el sentido de un "alejamiento" del presente para una aproximación al pasado.
} 


\section{perifèria}

Número 20 (2), diciembre 2015

revistes.uab.cat/periferia

\section{La escucha-apreciación ${ }^{18}$; del marco socio-musical hacia la categoría deunaalteridad temporal}

Como hemos dicho anteriormente, los colaboradores, cuyas autobiografías se construyen en sus recorridos narrativosdesde los comienzos de sus prácticas musicales hasta sus entradas y participaciones en la escena rock underground de la ciudad de Pelotas en los noventa, plantean una serie de comparaciones entre pasado y presente. Aunque sean variados y correspondan a la articulación de múltiples marcos socio-musicalescorrespondientes, plantaremos solamente uno ${ }^{19}$ : la escucha-apreciación musical.

Es interesante observar que, en el caso de nuestra investigación, aunque la escucha-apreciación sea planteada en narrativas cuyas autobiografías estén vinculadas a trayectorias musicales ancoradas en prácticas locales del rock, no seestablecen diferenciaciones dentro de marcos discursivos que generalmente enmarcan oposiciones valorativas entre géneros o sub-géneros musicales.Lo que hacen son interpretaciones-comparaciones que, desde el punto de vista de sus experiencias individuales, hacen emerger una red de interpretacióncuya complejidad entrelaza la escucha-apreciación con una serie de aspectos socioculturales que dan sentido a dicha actividadconel paso del tiempo.Más específicamente, seestablecen diferenciaciones que,basadas ensus percepciones de los cambios socio-culturales, remiten a hábitos de escucha pasados y presentes. 0 sea, hábitosque les ayudan a describir y significar prácticas musicales y ala construcción de una identidad colectiva del pasado común.

Se puede comprender dicha categoría (escucha-apreciación musical) a través de los planteamientos de Lilliestam (2013), Stockfelt (2004) y Becker (2010) acerca de los conceptos dehábitos musicales, modos adecuados de escucha y hábitos de

\footnotetext{
18 Empleamos el término escucha-apreciación en el mismo sentido en que es utilizado por los colaboradores en sus narrativas: un marco socio-cultural que en cada época implicauna serie de aspectos idiosincrásicos.

${ }^{19}$ Debido a las normas (el límite de páginas) editoriales para los autores.
} 


\section{perifèria}

Número 20 (2), diciembre 2015

revistes.uab.cat/periferia

escucha, respectivamente. Para Lilliestam (2013), los hábitos de escucha ${ }^{20}$ son conformados a través del background y experiencias en las cuales el sujeto está/estuvo expuesto ya las quegustó/aprendió a realizar (Bossius; Lilliestam apud Lilliestam 2013: 7); para Stockfelt (2004),los modos adecuados de escucha se constituyen a través de hábitos de escuchabasados en "las exigencias de una situación social dada y conforme a las convenciones socioculturales predominantes" en la subcultura en que el sujeto está sumergido (Stockfelt 2004: 91) y con la cual se identifica; Becker (2010), por su vez, observa que los hábitos de escucha son disposiciones-inclinaciones acerca de cómo los sujetos escuchan y se relacionanrespondena la música. Dichos hábitos son generalmente aprendidos a través de la imitación y de la interacción con aquellos que nos rodean. Por lo tanto, son prácticas de escucha que tienen que ver con el contexto socio-cultural compartido, con el espacio-tiempo y con la biografía personal de un sujeto (Becker 2010:134).

Es a través de las diferencias entre dichos hábitos de escucha-apreciaciónque se establece una alteridad temporal que, al fin, tiene que ver conuna identidad sociomusical (Hargreaves et al 2002).A continuación, presentamosuna selección de las narrativas de algunos colaboradores ${ }^{21}$.

Porto (2014) habla acerca de las diferencias entre el ayer y el hoy:

[...] Bueno, en aquella época, $[\ldots]$, la relación era muy diferente...iVaya!, tú ${ }^{22} \ldots$ te quedabas escuchando... el día entero prácticamente[risas] las $\operatorname{cosas}^{23}[\ldots] \ldots$ Como no tenías esa variedad [...] que se tiene hoy... [...] hasta una cierta saturación [...] de información... entonces tenías pocas informaciones,

\footnotetext{
${ }^{20}$ Enmarcados en los hábitos musicales.

21 Las traducciones fueron hechas en el sentido de mantener un equilibrio de entendimiento de los significados tanto en el español como en el portugués.

22 El pronombre personal tú es muchas veces utilizado para referirse alnosotros cuando explicando algo a alguien. Es como sise estuviera anunciandoa alguien (receptor) que si (éste) hubiera vivido en el contexto pasado del que habla (el emisor), las cosas serían "de ese modo".

${ }^{23}$ Los álbumes, etc.
} 


\section{perifèria}

Número 20 (2), diciembre 2015

revistes.uab.cat/periferia

entonces tú... la cosa de, por ejemplo, de escuchar el álbum entero [...]Hoy en día no tenemos más eso [...] de coger un álbum, un LP, por ejemplo, y quedarse acompañando música a música; la letra... Era otro tipo de relación [...] que tenías [...] con la música, [...] con los álbumes, principalmente... (Porto 2014: 00:33':57").

[...] El contacto [con los álbumes, $L P$, etc] [...] era muchísimo mayor de lo que hoy en día. [Cuando] escuchabas una cinta [casete], un LP, tú... te quedabas a escuchar [...] No te quedabas... no sé, leyendo otra cosa, como hoy en día [...]; haciendo... no sé... lavando la vajilla, [o] cualquier otra cosa: te sentabas, ponías la música y te quedabas escuchándola [...] Y creo que eso se ha perdido hoy. Tal vez sea una cosa que se hace cuando se es más joven... No lo sé... Pero se tenía esa, esa relación más de... apreciación mismo [...] Apreciabas el material de un modo más directo, digamos, [con] más... sinceridad... No sé cuál es la palabra...(Porto 2014: 00:35':36").

La selección de la narrativa de Porto (2014) presenta unos recuerdosimágenesacerca de los cambios en los hábitos de escucha-apreciaciónentre el ayerhoy. Las comparaciones remiten a una representaciónque tiene que ver con (1) un pasado en el cual se mantenía más compromisocon la música - en la práctica de la apreciación: el quedarse mucho tiempo escuchando ("el día entero"); escuchar los álbumes enteros, acompañando música a música, las letras; el ponerse a escuchar solamente la música, sin realizarninguna otra actividad; etc. Son términos que caracterizan hábitos de escucha-apreciaciónde su pasado basados en las ideas deescucha concentrada ${ }^{24}$, escucha intensa ${ }^{25}$ y apreciación holística ${ }^{26}$ que componen una relación de más sinceridad...

\footnotetext{
${ }^{24}$ En el sentido de fijar la atención a lo que se está haciendo.

${ }^{25}$ Que se realiza por horas.

${ }^{26}$ Que no se basa en sólo una actividad, sinoen varias.
} 


\section{revista de recerca i formació en antropologia}

\section{perifèria}

Número 20 (2), diciembre 2015

revistes.uab.cat/periferia

También Ilaman la atención los términosque explicitanlaalteridad temporalen su performance narrativa: un presente que remite a las pérdidas de una relación más ideal con la música. Pero también manifiesta una cierta ambigüedaden su punto de vista, en la medida en que considera que en elayer se mantenía más compromisotal vez por haber sido joven, por disponer demás tiempo para ello.

D’Avila (2014), así como Porto (2014), intensifican la representación de la pérdida de una relación ideal con la música. La escucha concentrada, en su narrativa, trae una imagen-recuerdo de un hábito de escucha-apreciación en su pasado que era definido por la escasez de materiales (vinilos, Lps, etc) ${ }^{27}$. De esa dificultad ${ }^{28}$ en obtener y poseer dichos materiales, emergía lo que entiende como aura ritual de la apreciación. Pero, con el paso del tiempo, dicha aura se fue perdiendo debido a las facilidades $^{29}$ que el hoy ofrece a la obtención de los materiales mencionados.Es como si se hubiera perdido un valor; un hábito de escucha como un valor debido a las dificultades en el pasado, que se ha disuelto debido a las facilidades en el presente. O sea, de la escasez venía el compromiso, el disfrutar-aprovechar un objeto de valor; de la abundancia viene el no-compromiso, el no-aprovechamiento del objeto, desvalorizando el objeto y la relación con el objeto (lo que llama de vulgarización):

[...]era [...] una experiencia que no... [...] se podía dar el lujo de perder. Si alguien te lo dijera así: 'Mira, voy a ponerte la música aquí, la pieza tal de... de Pink Floyd'. Te ponías a oírla. Aquello era el momento. Era un ritual. No se hablaba. No se decía ni pío [...]Entonces es lo que digo: ponías una atención...

\footnotetext{
27 En el guión de entrevista y entre tópicos como el acceso a materiales, instrumentos musicales, etc, emergen en prácticamente todas las narrativas las dificultades financieras personales, la falta de mercancías en el comercio musical de la ciudad, etc.

${ }^{28}$ Hay que decir que la dificultad aquí, se refiere también a la categoría dificultad que formaparte del entramado general de sentidos que profundizan las representaciones acerca del pasado. De esa forma, dicha categoría formaráparte de nuestro planteamiento a partir de ahora, aunque no esté explícita en las muestras de las narrativas que hemos presentadoen ese artículo.

${ }^{29}$ Es la categoría que pone uncontrapunto con la categoría dificultad.
} 


\section{perifèria}

Número 20 (2), diciembre 2015

revistes.uab.cat/periferia

concentrada [...]Hoy en día tú 'Ah, tengo la discografía completa de Pink Floyd en el ordenador...' pero ni la oye [...] O la pone como fondo [musical] para tomar cerveza y reírse [...].Sí, se ha cambiado ${ }^{30}[\ldots]$ Pero creo que la relación [...] con los medios de comunicación mismo, con el medio se ha cambiado. Entonces... hoy en día [...] el acceso a la súper-información... vulgarizó un poco la cosa del arte[...] (D'Avila 2014: 00:30':36").

Se puede comprender la pérdida del hábito de escucha-apreciación ideal como representación-consecuencia de una aperturaexcesivaque internet ha proporcionado. Un marco-acontecimiento significativo en sus memorias que a menudo enmarca la diferenciación entre épocas.

Por otro lado, la pérdida del sentido ritual del hábito de escucha-apreciación en el ayer(y relación con la música) es profundizada por D'Avila (2014) a través dela relación entre prácticas de escucha pasadas y presentes, así como con marcos de pensamiento de pensadores como Theodor Adorno y Walter Benjamin:

[...]Adorno dice: Si el proceso ya estaba un poco vulgarizado con la cosa [...] de la... regresión de la audición, [...] de la música, con el disco, con la reproducibilidad y tal $[\ldots]$ imagínate después $[\ldots],[\ldots]$ la $\operatorname{cosa}^{31}$ se ha convertido en telón de fondo [...]... No es más un momento [...] casi religioso...

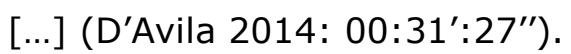

En los puntos de vista de Porto (2014) y D'Avila (2014), la representación de las pérdidas entre el ayer-hoy tiene que ver por lo tanto con un tipo de desacralización de la relación con la música.Dicha representación socio-musica/también es vista en laselección que sigue:

[...] La manera como yo... como nosotros... [...] creo que todos veíamos en aquella época de... en $1 a^{32}$ que el acceso era más difícil,... [...] creo que

\footnotetext{
${ }^{30}$ La relación con la música.

${ }^{31}$ La música y la relación con la música.

${ }^{32}$ Se refiere a la época de la que habla: fines de los años ochenta y noventa.
} 


\section{perifèria}

Número 20 (2), diciembre 2015

revistes.uab.cat/periferia

valorizábamos más... la obra... tipo, individual, de aquel disco $[\ldots],[\ldots]$ era un disco que íbamos a poner, oír...; oírlo de nuevo mañana; nosotros íbamos a oírlo entero de nuevo!... [risas] Nosotros oíamos e íbamos a descubrir cada detalle que había en aquel disco. [...] diferentemente de hoy, en que se tiene acceso a todo lo que exista... y, difícilmente vas a oír 10\% [risas]... y probablemente no estarás oyendo, vas a estar... lavando la vajilla, cocinando, barriendola casa y escuchando [...] [risas]...(Fernandes 2014: 00:49':29").

[...] Entonces creo que había esa relación... Por lo menos yo tenía esa relación con el disco [...]... de... en el momento en que lo ponía en el tocadiscos era como si fuera un altar aquello $[$ risas $][\ldots],[\ldots]$ lo ponía para oírlo entero... y analizar todo lo que estaba alrededor de... aquella obra $[\ldots],[\ldots]$ Tipo, oír al disco mirando la carátula, mirando alencarte ${ }^{33}$, mirando las letras,,.. cogiendo las revistas que tenía y buscando a todo lo que se hablaba sobre... aquel grupo $[\ldots] . .$. Entonces... creo que era eso $[\ldots]$, $[\ldots]$ : una relación más... nosotros poníamos más atención a la... a la obra. [...] (Fernandes 2014: 00:51':00").

Como hemos visto a lo largo de este apartado, las narrativas ejemplifican memorias socio-musicalesconstruidas a través de lo que hemos llamado hábitos de escuchaapreciación (categoría memorial). Dentro del conjunto de rasgos correspondientes a las prácticas musicales vividas, narradas y significadas, éstas manifiestan las premisas del diálogo entre los marcos sociales del pasado y el presente en la reconstrucción de parte de unamemoria social (Halbwachs 1990; 2004 [1925]; Candau 2011), así como dicho diálogo está en la base de la nostalgia(herramienta de relación de uno con su pasado y su presente, o sea, su trayectoria). En la perspectiva de la inseparabilidad entre memoriaeidentidad (Candau 2011), hemos visto que las narrativas, al mismo tiempo que reconstruyen memorias, (re)construyen identidades. O sea, concibenuna identidad colectiva como una (re)edificaciónde la "imagen de sí, para sí y para los otros" (Pollak 1992: 204) ${ }^{34}$ a

\footnotetext{
${ }^{33}$ Se refiere a las informaciones generales que habían en los estuches y carátulas de los discos de vinilo.

${ }^{34} \mathrm{O}$ sea, una construcción que ocurre a partir de: la "[...] imagen que uno adquiere a lo largo de su vida $[\ldots]$ " y que se "[...] refiere a sí mismo [...]"; "la imagen que uno construye y presenta a los otros y a sí
} 


\section{revista de recerca i formació en antropologia}

\section{perifèria}

Número 20 (2), diciembre 2015

revistes.uab.cat/periferia

través de los cambios que han percibido a lo largo del tiempo,enmarcando un juego entre el ayer y el hoy. Una alteridad temporalconstruida a través de representaciones alrededor de los hábitos de escucha-apreciación.

\section{Consideraciones finales y estructura de sentido memorial}

Como hemos dicho anteriormente, nuestro principal objetivo es el de comprender cómo se construye la memoria social de la escena rock underground pelotense en los noventa. Por otro lado, solamente hemos planteado en este artículo cuestiones relacionadas al hábito de escucha-apreciación como categoría memorial que no está directamente relacionada con la perspectiva de las escenas musicales. Aunque se trata deuna pequeña parte de la investigación realizada hasta ahora, creemos que se trata de un aspecto representativo de la alteridad temporalseñaladahasta aquí. Por lo tanto, vamos a presentar en este último apartado la estructura de sentido que emerge del conjunto de las narrativas. O sea, una estructura que, además de dicha alteridad, sustenta un entramado memorial de fondo que obra como apoyo a la inseparabilidad entre memoriaeidentidad. Solo es posible considerar dicho entramado en la medida en que las representaciones son compartidas, unas más similares y otras no. Por lo tanto, volveremos a la premisa básica de la antropología de la memoria: comprender, a través de una descripción densa, cómo los sujetos comparten una representación-estructura de sentido generalque lleva a la conformación de una textura memorial colectiva ${ }^{35}$.

En el caso de la categoría memorial hábitos de escucha-apreciación, podemos decir que las memorias operan un trabajo de diferenciación basado en percepciones

mismo y para creer en su propia representación, pero también para ser percibido de la manera como quiere ser percibido por los otros [...]"(Pollak 1992:204).

${ }^{35}$ Es importante decir que nuestra perspectiva de percepción y acceso a las representaciones desde el punto de vista colectivo está basada en las "características de las representaciones sociales distribuidas entre los sujetos" desde una perspectiva individual de acceso" (Wagner 1995: 9). O sea, nuestro interés está en el conjunto de "elementos comunes de conocimiento producidos por las personas", lo que Wagner (1995) clasifica como "representaciónprototípica individualmente distribuida" (Wagner 1995: 910). 


\section{perifèria}

Número 20 (2), diciembre 2015

revistes.uab.cat/periferia

acerca de los cambios ocurridos a través del tiempo. Las comparaciones en las performances narrativas llevan a la imagen de un paso del tiempo que ha conducido a una pérdida del valor de la música respecto a los cambios de hábitos de escucha-apreciación(marcos socio-musicales) que los colaboradores han percibido-concebido. En este punto, enmarcan una representación que,podríamos decir, emerge dela nostalgia (Pickering; Kinghtley 2006; Sedikides et al. 2004): la imagen de una cultura de escucha-apreciación pasada más positiva en relación a la que ocurre en el presente; de hábitos de escucha-apreciación que cambiaron hasta un deterioro de las relaciones de la gente con la música.

Los recuerdos-imágenes dibujan prácticas de escucha en el pasado, tales como laescucha concentrada, la escucha intensa y la apreciación holística, no solamente como perspectiva descriptiva de las prácticas en sí mismas, sinoque también adquierenel sentido de que aquellos que las realizabanmantenían una actitud de valoración de la música. En la medida en que enmarcan actitudes y valores ideales (concebidas a través de sus evaluaciones en el presente) frente a la música, dichos recuerdos también tienenrelación con la (re)construcción de sus identidades (basadas en unaalteridad temporal): una memoriaeidentidad que se construye en el reconocimiento de sus hábitos de escucha-apreciaciónen el pasado y de los sentidos que dichos hábitosadquierenbajo el reconocimiento de lainteraccióne interdependenciaque sus trayectorias de vida musicales tienen con las concepciones que han construido hasta hoy acerca de los hábitos de escucha-apreciación en el hoy ${ }^{36}$.

De este modo, la categoría hábitos de escucha-apreciación actúa, en ese trabajo de memoriacolectiva, como categoría que construye la representación de unos mismos dentro de las premisas de la memoriaeidentidad presentadas. Se puede decir que los hábitos de escucha-apreciación, además de ser una categoría memorial,están

\footnotetext{
${ }^{36}$ Basados en la premisa de las teorías de las representaciones sociales que sustentan la idea de que las representaciones tienen sus bases en las condiciones sociales (Wagner 1995: 2), se puede decir que dichas concepciones de los colaboradores tienen sus bases en las propias experiencias socio-culturales y musicales, así como con las relaciones que tuvieron con modos de pensamiento a lo largo del tiempo.
} 


\section{perifèria}

Número 20 (2), diciembre 2015

revistes.uab.cat/periferia

articulados como marco de representaciónde los aspectos socio-culturales que representan los propios oyentes-colaboradoresen sí mismos. O sea, ayudan a construir sus identidades musicales a través de prácticas socio-musicales que enmarcan relacionescon los otros y con el mundo fenomenológico (Becker 2010: 141). Y, de un modo más profundo, las representaciones construidas a través de dichos hábitos adquieren un rasgo ideológico, talcomo plantea Stockfelt (2004) respecto a los modos adecuados de escucha. O sea: están relacionados a conjuntos de opiniones-concepciones pertenecientes a grupos sociales y que tienen que ver con "relaciones ideales entre individuos, entre individuos y expresión cultural y entre expresiones culturales y la construcción de la sociedad" (Stockfelt 2004:92).

Finalmente, consideramos que la nostalgia, además de ser considerada como nostalgia grupal y articulada a través de los hábitos de escucha-apreciación, se caracteriza como una herramienta de relación, interpretación y significación de los vínculos que los sujetos tienen con el pasado y el presente, enlazando memoriaeidentidad bajo lo que hemos llamado alteridad temporal. Por lo tanto, aspectos del conjunto de las narrativas individuales que ayudan a tejer parte de la textura memorial colectiva con una semántica basada en la diferenciación entre épocas.

\section{Bibliografía}

Alberti, Verena. (2000). "Indivíduo e biografia na história oral". Fundação Getúlio Vargas - Sistema de bibliotecas. Disponible en: http://cpdoc.fgv.br/producao intelectual/arq/1525.pdf.

Becker, Judith (2010). "Exploring the habitus of listening" en Handbook of music and emotion. Theory, research, applications. Oxford: Oxford University Press, pp.xx-XX. DOI:10.1093/acprof:oso/9780199230143.001.0001

Bolívar, Antonio; Domingo, Jesús; Fernández, Manuel (2001). La investigación biográfico-narrativa en educación: enfoque y metodología. Madrid: Editorial La Muralla.

Candau, Jöel. (2005). Antropologia da Memória. Lisboa: Instituto Piaget.

Candau, Jöel. (2011). Memória e identidade. São Paulo: Contexto. 


\section{revista de recerca i formació en antropologia}

\section{perifèria}

Número 20 (2), diciembre 2015

revistes.uab.cat/periferia

Ferreira, Marieta de Moraes, Amado, Janaína. (1998) "Apresentação" en Usos e abusos da história oral. Rio de Janeiro: Editora da Fundação Getúlio Vargas, pp. viixxv.

Geertz, Clifford (2008). A interpretação das culturas. Rio de Janeiro: LTC.

Halbwachs, Maurice (1990). A memória coletiva. São Paulo: Edições Vértice.

Halbwachs, Maurice (2004). Los marcos sociales de La memoria. Rubí (Barcelona): Anthropos Editorial.

Hall, Stuart (2011). A identidade cultural na pós-modernidade. Rio de Janeiro: DP \& A Editora.

Hargreaves, David J.; Miell, Dorothy; Macdonald, Raymon A.R. (2002). "What are musical identities, and why are they important?" en Musical Identities. New York: Oxford University Press. DOI: 10.1093/oxfordhb/9780199730810.013.0008

Jovchelovitch, Sandra, Bauer, Martin. (2008). "Entrevista Narrativa" en Pesquisa Qualitativa com Texto, Imagem e Som: um manual prático. Petrópolis: Editora Vozes, pp. 90-113.

Lilliestam, Lars (2013). "Research on music listening: from typologies to interviews with real people". Volume!. vol.10, n.1, pp.1-23.DOI: 10.4000/volume.3733.

Lindon, Alicia (1999). "Narrativas autobiográficas, memoria y mitos: una aproximación a la acción social". Revista Economia, Sociedad y Territorio, vol.2, n.6, pp.295-310.

Pickering, Michael; Keightley, Emily (2006). "The Modalities of Nostalgia". Current Sociology. vol.54, n.6, pp.919-941.Doi: 10.1177/0011392106068458.

Pollak, Michael (1992). "Memória e identidade social". Estudos Históricos. vol.5, n.10, pp.200-212. Disponible en: http://bibliotecadigital.fgv.br/ojs/index.php/reh/article/view/1941/1080. 


\section{perifèria}

Número 20 (2), diciembre 2015

revistes.uab.cat/periferia

Portelli, Alessandro. (2010). "História Oral e Poder". Mnemosine. vol.6, n.2, pp.213.

en:

http://www.mnemosine.com.br/ojs/index.php/mnemosine/article/viewFile/198/pdf 183.

Sedikides, Constantine; Wildschut, Tim; Baden, Denise (2004). "Nostalgia: Conceptual Issues and Existential Functions" en Handbook of Experimental Existential Psychology.New York: Guilford Press, pp.200-214.

Stockfelt, Ola (2004). "Adequate modes of listening" en Audio culture: readings in modern music. New York: The continuum International Publishing Group Inc, pp.88-93.

Wagner, Wolfgang (1995). "Description, explanation and method in social representation research". Papers on Social Representations. vol.4, n.1, pp.156-176. Disponible en: http://www.psych.Ise.ac.uk/psr/PSR1995/4 1995Wagne.pdf. 